\title{
APSA Teaching and Learning Conference
}

\author{
Keynote Address
}

\author{
Steven Rathgeb Smith, Executive Director, APSA
}

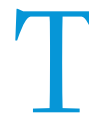
he occasion to deliver this address here at the 2014 Teaching and Learning Conference offered me the opportunity to reflect on my own teaching career. My first teaching experience was as a teaching assistant (TA) during my doctoral work in political science at MIT. I was a TA for many top-notch scholars and teachers, but my model for an exemplary lecturer was James Q. Wilson at Harvard University. Harvard's government department always needed TAs in American politics so they relied on graduate students from other universities. I was a TA for Wilson for three semesters, and I marveled at his brilliant, succinctly delivered 50-minute lectures for his American government class. The lectures were parsimonious but packed with information; I still have my notes from the lectures, almost 30 years later.

Despite Wilson's inspiration, I was like a lot of graduate students who during their doctoral work did not do take full responsibility for a lecture class during graduate school. Most of my TA work was leading discussion sections of larger classes. When I arrived at Duke University's public policy and political science departments in 1988, I had to learn on the job. Moreover, many of my classes were a smaller seminar size in which more interaction with the professor was expected. Here, the large lecture style of Wilson did not fit well. Furthermore, I was also teaching in a public policy program that stressed the intersection between theory and practice, so students were especially interested in the application of theories of public policy and political science to so-called real-world cases. This interest in applications led to my initial exposure to teaching cases. Some of my colleagues at Duke, including Bob Behn, used teaching cases initially developed from the Harvard's Kennedy School of Government to illustrate a wide variety of concepts from executive leadership to public-private partnerships to policy implementation. The late 1980 and early 1990 s was before the Internet so we had to order cases by directly calling the Kennedy School and placing an order.

Using teaching cases represented quite a shift in my teaching style. The classic Wilsonstyle lecture is a deductive form of learning with the professor at the center; the emphasis is on imparting information to the student as clearly and cogently as possible. The TA section is designed as a discussion opportunity when students ask questions and review the material presented in the lecture. In the discussion, the focus of the learning process remains on the lecture and the accompanying readings. But the use of teaching cases is a more inductive form of learning that shifts some of the learning process to the student. Typically, students are presented with a case scenario that requires a decision and students make a recommendation for action. Thus, in a case-method teaching approach, the professor does not primarily lecture but instead moderates a classroom discussion in which students analyze the case and offer different solutions or strategies. As a result, students develop a richer understanding of the dilemmas and principles involved in the decision and the case. Students are expected to marshal the necessary evidence to support their recommendation; memos can also be assigned that ask students to make their arguments in writing.

I started using the case teaching method at Duke but I still heavily relied on lectures or small seminar-type discussions. It was not a case-based teaching approach. Only when I moved to Seattle and the University of Washington did case-based teaching become more prominent in my teaching repertoire. I was teaching in a professional graduate program that especiallly lent itself to the casebased approach because many students were interested in "usable knowledge" to borrow from political scientist Charles Lindblom. I was teaching several new courses including nonprofit management, social policy, and political analysis. Over time, I broadened the topics addressed through the case teaching method to include collaboration; nonprofit advocacy; government-nonprofit relations; diversity in the public and nonprofit sectors; and interest group politics.

During the 1990 and early 200os, the universe of case teaching was relatively restricted and narrow. A few large research universities including Harvard University and the University of Washington had case repositories and the format was relatively standard: 10- to 15 -single-spaced pages, in print. Several important trends in higher education, however, have affected case teaching and its delivery. First, the internationalization of higher education and the growth of universities abroad that have their own case collections have led to greater diversity in cases around the world and the growth of the case-teaching method in many different countries. Indeed, in March 2013 I taught a class at the University of Hong Kong where I used mostly cases developed at the University of Hong Kong and other universities in Australia and Asia.

Second, the digital revolution has sharply reduced the transaction costs of producing cases. When I first started teaching in the 1980 s, one had to rely on case collections such as those of the Kennedy School because one could not reasonably create a case as a solo scholar because of the substantial resources it required. Now, access to information is remarkably quicker, cheaper, 


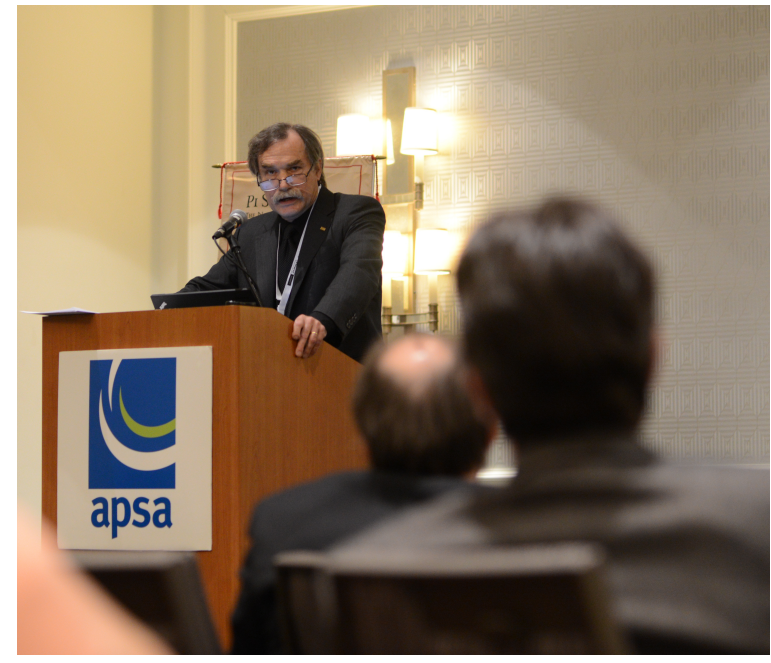

Steven Rathgeb Smith delivers the Keynote Address at the 2014 Teaching and Learning Conference in February 2014 in Philadephia. (Photo by Richard Houston for APSA.) and easier. Individual faculty members can assemble their own cases even without the help of a graduate student. This shift has also allowed greater diversity in the type of cases. To be sure, traditional printed cases still exist, but now many scholars have created "quasi-cases" that rely on newspaper articles and other material easily accessible through the Internet as a teaching case. My friend, Kent Weaver, at Georgetown University and the Brookings Institution, has created many different quasi-cases for teaching comparative policy and politics. For example, he has a quasi-case on coalition formation in Germany in which he uses various types of information including newspaper articles and other contemporary sources to run an in-class simulation in which students play different roles in the German Parliament.

Third, the digital revolution has allowed new technologies and approaches to be used with cases. I was fortunate to be involved in the development of an online teaching case that is part of the Hubert Project, hosted at the Humphrey School of Public Affairs at the University of Minnesota. This e-case, called "A New Advocacy Path at Treehouse," has three different modules with short video clips and relevant information pertaining to the development of an advocacy strategy for a nonprofit child welfare agency, Treehouse, based in Seattle, Washington. The case is designed to be used in a 9o-minute session on advocacy strategy, coalition development, and nonprofit management.

Fourth, the early cases in the 1980 s often focused on white male leaders in government and the nonprofit sectors. But the proliferation of cases in geographic focus, mode of delivery, and topic has offered the opportunity to greatly enhance gender, race, ethnicity, national origin, and sexuality representation in case content.

These significant trends affecting case teaching have direct relevance to the future of APSA, academic associations, and the role of teaching and learning within the association. When I joined APSA in 1982 as a young graduate student, the only way that I could obtain the APSA journals was by joining the association or going to the library where often I had to go through the laborious process of copying articles of interest. In those days, the value proposition of membership was tied to journal access and attendance at the annual meeting. The meeting was key to upward mobility in the profession and in the pre-Internet era, it was also a central place for access to new material. Many of our older members will remember the huge room at the annual meeting where APSA sold conference papers. Participants were expected to bring copies to the conference that could then be purchased by attendees. The meeting was also much smaller with the entire conference at the Washington Hilton Hotel or the Palmer House in Chicago.

In the intervening years, journal access and the annual meeting have changed dramatically. Just as I no longer need to go to the Kennedy School to find good cases, members can directly access APSA journals online through their libraries. Indeed, Cambridge University Press has digitized every publication ever issued by APSA including the original proceedings from the early $1900 \mathrm{~s}$ and the short-lived, but very interesting, Political Science Teacher, a quasi-newsletter from the 1980s. Cambridge sells this archive package directly to libraries. Overall, the digital revolution has meant the members have easy access to draft papers from a wide variety of sources; the annual meeting paper room is gone.

The annual meeting also has evolved with the growth of the profession. It is much more difficult to get on the meeting program. For example, we had more than 15 ,ooo separate submissions for the 2014 annual meeting from more than 8,200 different people. With the rise of quality indices, like impact factors, upward mobility in the profession is less tied to the annual meeting except for young scholars and scholars with active ongoing research projects, especially projects requiring collaboration among different scholars from different institutions. The diffusion of information means many outlets exist for information on research and teaching.

When I became a member of APSA, it was the only major political science association. But today, a political scientist has a choice of multiple associations both in the United States and abroad. I was recently in London and met with APSA Council member Ken Benoit who teaches at London School of Economics and Political Science and who has been quite involved in establishing the relatively new European Political Science Association. Many of the regional associations have been growing, and the APSA Teacher and Learning Conference is a relatively new development for the association and its members.

In short, APSA is faced with a markedly different value proposition for its members. I will address this important topic from a number of perspectives in the coming months in $P S$, the APSA newsletter, and other outlets. At the Teaching and Learning Conference I want to focus on the implications of these external trends and the changing value proposition for membership for both this conference and the place of teaching and learning within the association.

First, we need to think of the Teaching and Learning Conference as well as the annual meeting as more than a one-time event. For a long time, members, like me, attended the annual meeting for two or three days and then did not really think again about the meeting, except for the abstract submission in December, until the next annual meeting. We need to approach both the APSA Annual Meeting and the Teaching and Learning Conference as events rich in content that can be 
used for the benefits of members throughout the year. For instance, I have been working with APSA director of meetings and conferences, Lauren West and the annual meeting program co-chairs, Simon Jackman and Melanie Manion, to videotape key sessions and presentations at the annual meeting and then post this material on the APSA website with the goal of engaging the membership in ongoing conversations about the material. Similarly, Richard Houston from the APSA staff is videotaping various sessions of this Teaching and Learning Conference with the goal of posting this material on the website. Later, I hope that you and other members of the association will participate in a discussion of this material through various outlets including APSA Connect.

In addition, as an association, we need to diffuse the information and research on teaching and learning through many different outlets including the annual meeting, the APSA website, social media, and the communications strategy of the association with its members. Thus, I envision that the annual meeting will have more sessions including preconference workshops on teaching and learning. The association could also do more to recognize outstanding teachers at the annual meeting.

Also APSA is overhauling its website including its data management system and content management system. In my view, an increasingly critical role of the association's website is the diffusion of innovation regarding matters of importance to our members. Many presentations at this conference concern an innovative approach to teaching including the pre-conference workshopyesterday on MOOCs. Under the direction of APSA senior director for membership services and meetings, Liane Pinero-Kluge, we are also improving the capability of APSA
Connect to create a genuine ongoing community of people with similar interests including topics such as MOOCs or new approaches to online teaching.

The changing value proposition of membership requires APSA to think more broadly about professional development. We, of course, have had various types of professional development activities for a long time including this conference and the APSA Departmental Service Program. We at the association including senior director for academic programs, Jennifer Diascro, are reviewing new professional development strategies including perhaps a new mentoring program and a small-grants program for research on the profession including issues related to teaching and learning.

Jennifer Diascro and I are also reviewing our advocacy strategy at the association. We are very pleased that the Coburn amendment is gone but we realize that new challenges are likely to emerge regarding the National Science Foundation (NSF) and federal funding of political science research. One unfortunate consequence of the Coburn amendment was that at APSA our advocacy was focused, by necessity, on the fight to overturn the amendment. We also recognize that our advocacy cannot be defined by NSF or focused on NSF funding. Instead, a host of very important issues to political scientists at this conference and throughout the association are not directly related to federal research funding. Public policies on student loan programs, academic freedom, accreditation, performance assessment, and intellectual property are just a few of the many issues that are affecting our members. We recognize that the value proposition for members like you requires the active engagement of the association, its members, and leaders on a broad array of policy issues.
Finally, APSA needs to think creatively about how it can help create and support different types of communities within the association. Imentioned APSA Connect, but I regard the organized sections as critical to the future of the association. Therefore, we need to support the sections as sites of the exchange of information and the building of a community of people interested in similar issues including topics such as teaching and learning. When I entered the profession in 1982, the primary vehicle for creating this community was the annual meeting and to a much lesser extent the journals. The explosion of social media, the rapid pace of innovation, and the easy availability of new information, however, makes it incumbent upon us as an association to use new technologies to create multiple communities of members.

I greatly appreciate this opportunity to speak to you today and look forward to working with you in the future. Thank you very much. I welcome your questions.

\section{ACKNOWLEDGMENTS}

I would like to thank the conference program committee including its chair, Victor Asal, for inviting me to give this keynote speech. I would also like to thank the APSA staff for their excellent work in support of this conference and my participation in particular. I would also like to extend a special thanks to Kimberly Mealy of the APSA staff for her ongoing support of this conference and its attendees. I am also very honored to be presenting the keynote address, given the long line of distinguished political scientists who have given this keynote including Michael Brintnall at last year's conference and Rogers Smith in 2010. 